\title{
Optimal military spending, trade and stochastic economic growth
}

\author{
Deng-Shan Wang ${ }^{1 *}$ Yan Wang ${ }^{1}$, Yifang Liu ${ }^{2}$, Heng-fu Zou ${ }^{1}$ \\ ${ }^{1}$ CEMA, Central University of Finance and Economics, Beijing 100081 China \\ ${ }^{2}$ School of Economics, Central University of Finance and Economics, Beijing 100081 China
}

\begin{abstract}
In this paper, based on dynamic programming we investigate the military spending, trade and wealth accumulation in a stochastic endogenous growth model. For the CobbDauglas utility function, explicit solutions of the optimal problem in the home country are obtained, and the optimal consumptions of domestic goods and foreign goods, the share of domestic capital stock and foreign bond holdings are derived. The comparative dynamic analysis shows that when intertemporal substitution in consumption is relative elastic, the lower the foreign military spending, the higher variance of foreign military spending and lower volatility in the return of capital or bonds will result in lower consumption ratio and higher economic growth rate.
\end{abstract}

Keywords: Military spending; Wealth accumulation; Trade; Foreign bond holdings; Stochastic economic growth

JEL classification: E20; E22; H56; O10; O40

\section{Introduction}

The relationship among military spending, armament races and economic growth has received considerable attention. This topic has been studied widely both in economics and in the political science. Dating back to 1960s, Richardson (1960) and Saaty (1968) started to use mathematical models to solve the theoretical problem of arms race. Following the Richardson's arms race model, Brito (1972), Intriligator (1975), Intriligator and Brito (1976), use the dynamic model under the background of the east-west conflicts to find the stable equilibrium. Simaan and Cruz (1975) and van der Ploeg and de Zeeuw (1990) consider the existence of a Nash equilibrium solution from a differential game viewpoint. A major

*E-mail: wangdsh1980@yahoo.com.cn 
innovation of Deger and Sen (1984) is to analyze the asymmetric reaction function of two "unequal" size countries. Zou (1995) has investigated the arms accumulation effect on investment and capital accumulation, and found that capital accumulation is independent of the military spending in the long run. Chang, Tsai and Lait (1996) examine the dynamic effects of an anticipated foreign military shock. Recently, Gong and Zou (2003) studies the military spending and economic growth in a stochastic endogenous growth model, and the introduction of stochastic elements produces different analytical results. Lee (2007) has proved that the differential game model has an unstable equilibrium, a result opposite of Deger and Sen (1984). Shieh, Chang and Lai (2007) have found that the key factor determining the steady state and economic growth rate, is the degree of relative risk aversion. Lin and Lee (2012) have stated that military spending affects economic growth through the crowding-out effect, the spin-off effect and the resource mobilization effect, and have demonstrated that there exists an optimal defence burden, which depends on the degree of risk preference.

Meanwhile, a number of research contributions have been made in empirical analysis and policy analysis. Benoit (1973,1977), Kennedy (1974) and Deger and Sen (1983), have shown that higher defence spending stimulates economic growth of domestic country. Employing a VAR analysis, Srilanka, Wijeweera and Webb (2009) have found that military spending exerts only a minimal positive impact on real GDP. Alptekin and Levine (2012) have demonstrated that the hypothesis of a positive effect of military expenditure on economic growth is supported for developed countries. However, Deger (1979), Deger and Smith (1980) and Faini, Annez and Taylor (1980), has used mathematical models and macro-statistical evidence to show that an increase in military expenditure may hinder development in the Third World. Abu-Bader and Abu-Qarn (2003) also have demonstrated that the wars slow down the economy of Egypt, Isreal and Syria, for the past three decades. In the work of Polachek and Sevastianova (2012), the estimates indicate that civil war reduces annual growth by 0.01-0.13 percentage points, and high-intensity inter-state conflict reduces annual growth by 0.18-2.77 percentage points. Furthermore, Landau (1993) has demonstrated that there exists a quadratic relationship between military expenditure and economic growth through the datum of 71 countries.

Recent years, the conflicts of islands between China-Japan and Korea-Japan are becoming increasingly fierce. In order to protect their national interests, each country of them increases the military expenditures. The conflicts between them have a long history, but their dependency of trade and economic is not weaken. With economic globalization, these phenomenon happen commonly in many local areas of the world. Inspired by the European debt crisis, we must pay more attention to the influence of holding foreign bonds. Thus, adding trade and bond holdings to military spending and stochastic growth model is meaningful. At the same time, the stochastic setting on arms accumulates, capital return and bonds return makes our model more realistic. In addition, the thought and method in Gong and Zou (2003) provide us much inspiration.

The purpose of this paper is to present the endogenous stochastic economic growth problem of the home country in two-country military competitive model based on dynamic 
programming. In our model, we assume that the two countries, the home country and the foreign country, are in the state of military confrontation, and they trade with each other. Besides consuming domestic goods, the home country also consume foreign goods through trade. The total wealth of the home country consists of two parts, domestic capital stock and holding foreign bonds. More importantly, the military spending for the home country is regarded as special consumption goods. Based on the method of Grinols and Turnovsky (1993) and Gong and Zou (2003), we take a specific example to analyze the optimal solutions and the effects of different factors on economic growth.

The remaining of this paper is organized as follows. Section 2 presents the background and sets up our model. In Section 3, using the dynamic optimization method, we introduce the value function and find the Hamilton-Jacobi-Bellman equation. In Section 4, we specify the utility function and technology to get the explicit solutions to the optimal problem. We also use comparative dynamics analysis to study the effects of stochastic factors on the economic growth in the home country. We summarize the main results in Section 5.

\section{The theoretical model}

There are two countries in our model, the home country and the foreign country. We assume that they are in the state of military confrontation, but they trade with each other. We regard military expenditure as consumption goods, and the utility function of the home country depends upon civilian consumption allocation as well as "security" and "threat". Compared with the conventional model, the home country consumes domestic goods and foreign goods in our small open economy model. We assume that the utility function of the home country is $u\left(c_{h}, c_{f}, m, m^{*}\right)$, where $c_{h}$ is the consumption of domestic goods, $c_{f}$ is the consumption of foreign goods, $m$ is the military spending of the home country, and $m^{*}$ is the military spending of the foreign country.

Following the work of Zou (1995) and Gong and Zou (2003), suppose the utility function $u\left(c_{h}, c_{f}, m, m^{*}\right)$ is twice differentiable, concave and satisfies

$$
u_{1}>0, u_{2}>0, u_{3}>0, u_{4}<0, u_{11}<0, u_{22}<0, u_{33}<0, u_{44}<0,
$$

which means that the marginal utility of the home country from its consumption of domestic goods and foreign goods and military spending is positive and diminishing. However, the marginal utility from the military spending of the foreign country (i.e. foreign military threat) is negative and diminishing. Obviously, the higher the military spending of the home country is, the more securities the home country's people think. The higher the military spending of the foreign country is, the more dangers the home country's people think. Similarly, additional military spending of the foreign country leads to more threat to the home country

$$
u_{12}>0, u_{13}>0, u_{14}<0, u_{23}>0, u_{24}<0, u_{34}>0 .
$$


The expressions $u_{13}=u_{31}>0$ and $u_{23}=u_{32}>0$ mean that a rise in security for the home country increases its marginal utility of consumption of domestic goods and foreign goods. The assumption $u_{14}=u_{41}<0$ and $u_{24}=u_{42}<0$ imply that more foreign military threat decreases the home country's marginal utility of consumption of domestic goods and foreign goods. Finally, $u_{34}=u_{43}>0$ states that an increase in the foreign military threat will increase the marginal utility of the home country's defense.

According to the work of Eaton(1981), Turnovsky(2000) and Gong and Zou (2003), production function can be expressed by stochastic economic growth model

$$
d Y=F(k) d t+G(k) d y, \quad F^{\prime}(k)>0, F^{\prime \prime}(k)<0 .
$$

From this equation, we find that the output during the period $(t, t+d t)$ consists of two parts. Firstly, $F(k)$ represents the deterministic part, which means the average output in units of time. Secondly, $G(k) d y$ stands for the stochastic part, which reflects the stochastic factors' effects on output. We assume the stochastic term $d y$ is temporally independent, normally distributed, stochastic process with mean zero and variance $\sigma_{y}^{2} d t$. In order to specify the technology, we assume the production function satisfies $A K$ model, that is, $F(k)=A k, G(k)=A k$.

In the open economy, the home country purchases government bonds from the foreign country to earn interests. For the home country, the returns on capital and foreign bond holdings are stochastic, but the military spending of the home country is not random. We also assume that

(1) The home country's total wealth satisfies $W=k+q b$, where $k$ is the home country's capital stock, $b$ is the amount of foreign bond holdings of the home country and $q$ is the endogenously determined variable price of foreign bonds.

(2) The real rate of return on capital of the home country is

$$
d R_{k}=r_{k} d t+d u_{k}
$$

where $r_{k}$ is the average rate of return on capital in units of time, and $d u_{k}$ is an independent, normally distributed, stochastic process with mean zero and variance $\sigma_{k}^{2} d t$. According to the $A K$ production function, we get $r_{k}=A, d u_{k}=A d y$.

(3) The real rate of return on the foreign bond holdings of the home country is

$$
d R_{b}=r_{b} d t+d u_{b}
$$

where $r_{b}$ is the average rate of return on foreign bond holdings in units of time, and $d u_{b}$ is an independent, normally distributed, stochastic process with mean zero and variance $\sigma_{b}^{2} d t$.

In the present paper, we regard the military spending as consumption goods, so the home country's total wealth satisfies

$$
d W=W\left(n_{1} d R_{k}+n_{2} d R_{b}\right)-c_{h} d t-p c_{f} d t-m d t
$$


where $n_{1}=\frac{k}{W}$ is the share of capital on total wealth, $n_{2}=\frac{q b}{W}$ is the share of foreign bond holdings on the total wealth, and $p$ is the relative price of foreign goods.

Inserting $d R_{k}, d R_{b}$ into equation (6), we have

$$
\frac{d W}{W}=\left(n_{1} r_{k}+n_{2} r_{b}-\frac{c_{h}+p c_{f}+m}{W}\right) d t+n_{1} d u_{k}+n_{2} d u_{b},
$$

where $n_{1}+n_{2}=1$.

Simplifying equation (7), we have

$$
d W=g W d t+W d w
$$

where

$$
\begin{gathered}
g=n_{1} r_{k}+n_{2} r_{b}-\frac{c_{h}+p c_{f}+m}{W}, \\
d w=n_{1} d u_{k}+n_{2} d u_{b} .
\end{gathered}
$$

For the home country, we assume there are kinds of random factors determined by the foreign country's conditions. Furthermore, we suppose the foreign military spending $m^{*}$ is exogenous and satisfies a stochastic process

$$
d m^{*}=\alpha m^{*} d t+\sigma_{m^{*}} m^{*} d u_{m^{*}}
$$

where $\alpha m^{*} d t$ means the known average level of foreign military spending, and $\sigma m^{*} d u_{m^{*}}$ stands for the stochastic part. The term $d u_{m^{*}}$ is an independent, normally distributed, stochastic process with mean zero and variance $\sigma^{2} d t$.

We denote

$$
\begin{gathered}
\mu=\lim _{d t \rightarrow 0} \frac{E(d w)^{2}}{d t} \\
=\lim _{d t \rightarrow 0} \frac{E\left(n_{1} d u_{k}+n_{2} d u_{b}\right)^{2}}{d t} \\
=n_{1}^{2} \sigma_{k}^{2}+n_{2}^{2} \sigma_{b}^{2}+2 n_{1} n_{2} \sigma_{k b},
\end{gathered}
$$

and

$$
\operatorname{cov}\left(d u_{i}, d u_{j}\right)=\sigma_{i j} d t, \quad \operatorname{cov}\left(d W, d u_{j}\right)=\sigma_{W j} d t, \quad i, j=k, b, m^{*} .
$$

The home country maximizes its discounted welfare with a constant time discount rate $\rho$ with $0<\rho<1$ as

$$
\max \quad E_{0} \int_{0}^{\infty} u\left(c_{h}, c_{f}, m, m^{*}\right) e^{-\rho t} d t
$$

subject to

$$
d W=g W d t+W d w
$$




$$
d m^{*}=\alpha m^{*} d t+\sigma_{m^{*}} m^{*} d u_{m^{*}}
$$

with

$$
\begin{gathered}
g=n_{1} r_{k}+n_{2} r_{b}-\frac{c_{h}+p c_{f}+m}{W}, \\
d w=n_{1} d u_{k}+n_{2} d u_{b}, \\
n_{1}+n_{2}=1 .
\end{gathered}
$$

The home country chooses the consumption path of domestic goods $c_{h}$ and foreign goods $c_{f}$, wealth accumulation path $W(t)$ (including capital accumulation path $k(t)$ and foreign bond holdings path $b(t)$ ), and the military spending path of home country $m(t)$, to maximize its discount utility in (13). Here the initial capital stock and foreign bond holdings in the home country are given by $k(0)$ and $b(0)$, respectively.

\section{Optimization problem}

To solve the optimization problem (13) above, we denote the value function (also named indirect utility function) $V\left(W, m^{*}, t\right)$, and define the differential operator of this function by

$$
\begin{gathered}
L\left(V\left(W, m^{*}, t\right)\right)=\lim _{d t \rightarrow 0} E\left(\frac{d V}{d t}\right) \\
=V_{t}+V_{W} g W+V_{m^{*}} \alpha m^{*}+V_{W m^{*}} \sigma_{W m^{*}} m^{*} W+\frac{1}{2} V_{W W} \mu W^{2}+\frac{1}{2} V_{m^{*} m^{*}} \sigma_{m^{*}}^{2} m^{* 2},
\end{gathered}
$$

where $\sigma_{W m^{*}}=n_{1} \sigma_{k m^{*}}+n_{2} \sigma_{b m^{*}}$ and $\mu$ satisfies expression (12).

Reminding the exponential time discounting $e^{-\rho t}$, assume the value function is

$$
V\left(W, m^{*}, t\right)=X\left(W, m^{*}\right) e^{-\rho t} .
$$

Thus, the problem becomes that the home country chooses consumption of domestic goods and foreign goods, military spending and the shares of capital and foreign bond holdings, to maximize the following expression

$$
\begin{gathered}
e^{-\rho t}\left[u\left(c_{h}, c_{f}, m, m^{*}\right)+L\left(X\left(W, m^{*}\right) e^{-\rho t}\right)+\frac{\eta}{\rho}\left(1-n_{1}-n_{2}\right)\right] \\
=e^{-\rho t}\left[u\left(c_{h}, c_{f}, m, m^{*}\right)-\rho X+X_{W} g W+X_{m^{*}} \alpha m^{*}+X_{W m^{*}} \sigma_{W m^{*}} m^{*} W\right. \\
\left.+\frac{1}{2} X_{W W} \mu W^{2}+\frac{1}{2} X_{m^{*} m^{*}} \sigma_{m^{*}}^{2} m^{* 2}+\frac{\eta}{\rho}\left(1-n_{1}-n_{2}\right)\right],
\end{gathered}
$$

where $\eta$ is the Lagrange multiplier for the identity of the total shares.

In order to get the optimal solution to the optimization problem (13), taking partial derivatives with respect to $c_{h}, c_{f}, m, n_{1}, n_{2}$, we get 


$$
\begin{gathered}
\frac{\partial u\left(c_{h}, c_{f}, m, m^{*}\right)}{\partial c_{h}}=X_{W}, \\
\frac{\partial u\left(c_{h}, c_{f}, m, m^{*}\right)}{\partial c_{f}}=p X_{W}, \\
\frac{\partial u\left(c_{h}, c_{f}, m, m^{*}\right)}{\partial m}=X_{W}, \\
X_{W W}\left(n_{1} \sigma_{k}^{2}+n_{2} \sigma_{k b}\right) W^{2}+X_{W} r_{k} W=\frac{\eta}{\rho}, \\
X_{W W}\left(n_{2} \sigma_{b}^{2}+n_{1} \sigma_{k b}\right) W^{2}+X_{W} r_{b} W=\frac{\eta}{\rho},
\end{gathered}
$$

which asserts that the marginal value of consumption of domestic goods equals to that of the military spending at the optimal condition, and the marginal value of consumption of foreign goods equals to $p$ times marginal value of the military spending at the optimal condition. According to the basic principle of dynamic optimization, the value function satisfies Hamilton-Jacobi-Bellman equation

$$
\max e^{-\rho t}\left[u\left(c_{h}, c_{f}, m, m^{*}\right)+L\left(X\left(k, m^{*}\right) e^{-\rho t}\right)+\frac{\eta}{\rho}\left(1-n_{1}-n_{2}\right)\right]=0 .
$$

From equation (15), we can calculate the optimal solutions for $c_{h}, c_{f}, m, n_{1}, n_{2}$. Thus, the Hamilton-Jacobi-Bellman equation above becomes

$$
\begin{gathered}
e^{-\rho t}\left[u\left(\widetilde{c_{h}}, \widetilde{c_{f}}, \widetilde{m}, m^{*}\right)-\rho X+X_{W} g W+X_{m^{*}} \alpha m^{*}+X_{W m^{*}} \sigma_{W m^{*}} m^{*} W\right. \\
\left.+\frac{1}{2} X_{W W} \mu W^{2}+\frac{1}{2} X_{m^{*} m^{*}} \sigma_{m^{*}}^{2} m^{* 2}+\frac{\eta}{\rho}\left(1-\widetilde{n_{1}}-\widetilde{n_{2}}\right)\right]=0,
\end{gathered}
$$

where the symbol $\sim$ stands for the optimal value.

\section{Specific example}

In order to get the explicit solution to the optimization problem (13), we use the CobbDauglas function to specify the utility function as

$$
u\left(c_{h}, c_{f}, m, m^{*}\right)=\frac{1}{1-\gamma}\left(c_{f}^{\sigma} c_{h}^{\theta} m^{1-\sigma-\theta}\right)^{1-\gamma}\left(m^{*}\right)^{-\lambda},
$$

where $0<\theta<1 ; \lambda>0$ when $0<\gamma<1, \lambda<0$ when $\gamma>1$. Because of $\partial u / \partial m^{*}<0$, we must restrict $\gamma$ and $\lambda$ in this way. 
As above, there are two budget constraints

$$
\begin{gathered}
d W=W\left(n_{1} d R_{k}+n_{2} d R_{b}\right)-c_{h} d t-p c_{f} d t-m d t, \\
d m^{*}=\alpha m^{*} d t+\sigma_{m^{*}} m^{*} d u_{m^{*}},
\end{gathered}
$$

where $n_{1}=\frac{k}{W}, n_{2}=\frac{q b}{W}$ and $n_{1}+n_{2}=1$.

\subsection{Explicit solutions}

Similar to the work of Merton (1971) and Turnovsky (1993), we assume the value function $X\left(W, m^{*}\right)$ is of the following form

$$
X\left(W, m^{*}\right)=\delta W^{1-\gamma}\left(m^{*}\right)^{-\lambda},
$$

where $\delta$ is a constant to be determined. Then, we have

$$
\begin{gathered}
X_{W}=\delta(1-\gamma) W^{-\gamma}\left(m^{*}\right)^{-\lambda}, \quad X_{W W}=-\delta(1-\gamma) \gamma W^{-\gamma-1}\left(m^{*}\right)^{-\lambda} \\
X_{m^{*}}=-\delta \lambda W^{1-\gamma}\left(m^{*}\right)^{-1-\lambda}, \quad X_{m^{*} m^{*}}=\delta \lambda(1+\lambda) W^{1-\gamma}\left(m^{*}\right)^{-2-\lambda} \\
X_{W m^{*}}=-\delta \lambda(1-\gamma) W^{-\gamma}\left(m^{*}\right)^{-1-\lambda} .
\end{gathered}
$$

Using equation (20) the optimal condition (15) becomes

$$
\begin{gathered}
\theta c_{f}^{\sigma(1-\gamma)} c_{h}^{\theta(1-\gamma)-1} m^{(1-\sigma-\theta)(1-\gamma)}\left(m^{*}\right)^{-\lambda}=X_{W}, \\
\sigma c_{f}^{\sigma(1-\gamma)-1} c_{h}^{\theta(1-\gamma)} m^{(1-\theta-\sigma)(1-\gamma)}\left(m^{*}\right)^{-\lambda}=p X_{W}, \\
(1-\sigma-\theta) c_{f}^{\sigma(1-\gamma)} c_{h}^{\theta(1-\gamma)} m^{(1-\sigma-\theta)(1-\gamma)-1}\left(m^{*}\right)^{-\lambda}=X_{W} \\
{\left[-\delta(1-\gamma) \gamma\left(m^{*}\right)^{-\lambda}\left(n_{1} \sigma_{k}^{2}+n_{2} \sigma_{k b}\right)+\delta(1-\gamma)\left(m^{*}\right)^{-\lambda} r_{k}\right] W^{1-\gamma}=\frac{\eta}{\rho},} \\
{\left[-\delta(1-\gamma) \gamma\left(m^{*}\right)^{-\lambda}\left(n_{2} \sigma_{b}^{2}+n_{1} \sigma_{k b}\right)+\delta(1-\gamma)\left(m^{*}\right)^{-\lambda} r_{b}\right] W^{1-\gamma}=\frac{\eta}{\rho},}
\end{gathered}
$$

where $n_{1}+n_{2}=1$.

From equation (21) we can calculate the proportions of the two kinds of goods consumption and military spending in total consumption as

$$
c_{h}=\theta C, \quad c_{f}=\frac{\sigma}{p} C, \quad m=(1-\theta-\sigma) C,
$$


where $C=c_{h}+p c_{f}+m$.

Recalling $n_{1}+n_{2}=1$, we find that $n_{1}$ and $n_{2}$ satisfy

$$
\begin{aligned}
& n_{1}=\frac{k}{W}=\frac{r_{k}-r_{b}+\gamma \sigma_{b}^{2}-\gamma \sigma_{k b}}{\gamma \sigma_{b}^{2}-2 \gamma \sigma_{k b}+\gamma \sigma_{k}^{2}}, \\
& n_{2}=\frac{q b}{W}=\frac{\gamma \sigma_{k}^{2}-\gamma \sigma_{k b}-r_{k}+r_{b}}{\gamma \sigma_{b}^{2}-2 \gamma \sigma_{k b}+\gamma \sigma_{k}^{2}} .
\end{aligned}
$$

According to the third equation in (21) and first equation in (20), we obtain

$$
\frac{C}{W}=\left[\frac{A(1-\sigma-\theta)}{\delta(1-\gamma)}\right]^{\frac{1}{\gamma}}
$$

where

$$
A=\left(\frac{\sigma}{p}\right)^{\sigma(1-\gamma)} \theta^{\theta(1-\gamma)}(1-\theta-\sigma)^{(1-\sigma-\theta)(1-\gamma)-1} .
$$

Substituting equations (17), (19) and (20) into equation (16), we have

$$
\begin{gathered}
\frac{1}{1-\gamma}(1-\theta-\sigma) A C^{1-\gamma}\left(m^{*}\right)^{-\lambda}-\rho \delta W^{1-\gamma}\left(m^{*}\right)^{-\lambda} \\
+\delta(1-\gamma) W^{-\gamma}\left(m^{*}\right)^{-\lambda} g W-\delta \lambda W^{1-\gamma}\left(m^{*}\right)^{-1-\lambda} \alpha m^{*} \\
-\delta \lambda(1-\gamma) W^{-\gamma}\left(m^{*}\right)^{-1-\lambda} \sigma_{W m^{*}} m^{*} W \\
-\frac{1}{2} \delta(1-\gamma) \gamma W^{-\gamma-1}\left(m^{*}\right)^{-\lambda} \mu W^{2}+\frac{1}{2} \delta \lambda(1+\lambda) W^{1-\gamma}\left(m^{*}\right)^{-2-\lambda} \sigma_{m^{*}}^{2} m^{* 2}=0
\end{gathered}
$$

where $\mu$ satisfies equation (12).

Solving this equation for the ratio of total consumption to the total wealth, we get

$$
\frac{C}{W}=\left[\frac{\rho \delta-g \delta(1-\gamma)+\alpha \delta \lambda+\delta \lambda(1-\gamma) \sigma_{W m^{*}}+\frac{1}{2} \delta \gamma(1-\gamma) \mu-\frac{1}{2} \delta(1+\lambda) \lambda \sigma_{m^{*}}^{2}}{\frac{1}{1-\gamma} A(1-\sigma-\theta)}\right]^{\frac{1}{1-\gamma}}
$$

Then, using equation(25) we can determine the coefficient $\delta$ as

$$
\delta=\frac{A(1-\sigma-\theta)}{(1-\gamma)\left[\rho-g(1-\gamma)+\alpha \lambda+\lambda(1-\gamma) \sigma_{W m^{*}}+\frac{1}{2} \gamma(1-\gamma) \mu-\frac{1}{2}(1+\lambda) \lambda \sigma_{m^{*}}^{2}\right]^{\gamma}}
$$

where the coefficient $A$ is determined by equation (26).

If we denote $M=\rho-g(1-\gamma)+\alpha \lambda+\lambda(1-\gamma) \sigma_{W m^{*}}+\frac{1}{2} \gamma(1-\gamma) \mu-\frac{1}{2}(1+\lambda) \lambda \sigma_{m^{*}}^{2}$, the coefficient $\delta$ in equation (19) can be simplified to the expression

$$
\delta=\frac{A(1-\sigma-\theta)}{(1-\gamma) M^{\gamma}}
$$


Hence, combining equations (25) and (29) yields

$$
\frac{C}{W}=\left[\frac{A(1-\sigma-\theta)}{\delta(1-\gamma)}\right]^{\frac{1}{\gamma}}=M
$$

We can also obtain the ratio of $c_{h}, c_{f}, m$ to total wealth $W$ as

$$
\begin{gathered}
\frac{c_{h}}{W}=\theta \frac{C}{W}=\theta M, \\
\frac{c_{f}}{W}=\frac{\sigma}{p} \frac{C}{W}=\frac{\sigma M}{p} \\
\frac{m}{W}=1-\theta-\sigma \frac{C}{W}=(1-\sigma-\theta) M .
\end{gathered}
$$

Therefore, the following proposition summarizes the solution to the dynamic optimization problem (13) with (17).

Proposition. Assuming that the home country and the foreign country are in the state of military confrontation, but they trade with each other as well. To solve the maximization problem for the home country, we denote the consumption of domestic goods as $c_{h}$, the consumption of foreign goods as $c_{f}$, the foreign bond holdings of the home country as $b(t)$, the stock capital of the home country as $k(t)$, the military spending of the home country as $m$, and the military spending of foreign country as $m^{*}$. If we use the Cobb-Dauglas function in equation (17) to express the home country's utility function, the home country's optimization problem (13) becomes that it maximizes the expected utility

$$
\max E_{0} \int_{0}^{\infty} e^{-\rho t} \frac{1}{1-\gamma}\left(c_{f}^{\sigma} c_{h}^{\theta} m^{1-\sigma-\theta}\right)^{1-\gamma}\left(m^{*}\right)^{-\lambda} d t
$$

subject to the wealth accumulation equation (6), foreign country's military capital accumulation function (11), and total wealth function $W=k+q b$. The $n_{1}$ and $n_{2}$ in equation (6) stand respectively for the share of capital on total wealth and the share of foreign bond holdings on the total wealth. Therefore, the optimal solutions of this dynamic optimization problem are

The ratio of the optimal consumption of domestic goods in the home country is

$$
\frac{c_{h}}{W}=\theta M
$$

The ratio of the optimal consumption of foreign goods in the home country is

$$
\frac{c_{f}}{W}=\frac{\sigma M}{p} .
$$

The ratio of the optimal military spending in the home country is 


$$
\frac{m}{W}=(1-\sigma-\theta) M
$$

The proportion of total consumption $C=c_{h}+c_{f}+m$ to the total wealth is

$$
\frac{C}{W}=M
$$

where $M=\rho-g(1-\gamma)+\alpha \lambda+\lambda(1-\gamma) \sigma_{W m^{*}}+\frac{1}{2} \gamma(1-\gamma) \mu-\frac{1}{2}(1+\lambda) \lambda \sigma_{m^{*}}^{2}$.

In addition, the home country's optimal share of capital and optimal share of holding foreign bonds are

$$
\begin{aligned}
& n_{1}=\frac{k}{W}=\frac{r_{k}-r_{b}+\gamma \sigma_{b}^{2}-\gamma \sigma_{k b}}{\gamma \sigma_{b}^{2}-2 \gamma \sigma_{k b}+\gamma \sigma_{k}^{2}}, \\
& n_{2}=\frac{q b}{W}=\frac{\gamma \sigma_{k}^{2}-\gamma \sigma_{k b}-r_{k}+r_{b}}{\gamma \sigma_{b}^{2}-2 \gamma \sigma_{k b}+\gamma \sigma_{k}^{2}} .
\end{aligned}
$$

\subsection{Comparative dynamics}

The dynamic growth equation for the total wealth can be written as

$$
\begin{aligned}
d W & =W\left(n_{1} d R_{k}+n_{2} d R_{b}\right)-c_{h} d t-p c_{f} d t-m d t \\
& =W\left[\left(n_{1} r_{k}+n_{2} r_{b}-\frac{C}{W}\right) d t+n_{1} d u_{k}+n_{2} d u_{b}\right] .
\end{aligned}
$$

We denote the expected growth rate of total wealth stock and total consumption as $\phi$. Since $\frac{C}{W}$ determined by exogenous constants, the proportion between $C$ and $W$ doesn't change through time. Hence, the growth rate of total consumption $C$ equals to the growth rate of total wealth $W$ as

$$
\phi=E\left(\frac{\dot{W}}{W}\right)=E\left(\frac{\dot{C}}{C}\right)=n_{1} r_{k}+n_{2} r_{b}-\frac{C}{W},
$$

where $\dot{W}=d W / d t$ and $\dot{C}=d C / d t$.

By considering the comparative dynamics, we can discuss how military spending and stochastic shocks affect the economy in equilibrium. According to $\frac{C}{W}=M=\rho-g(1-\gamma)+$ $\alpha \lambda+\lambda(1-\gamma) \sigma_{W m^{*}}+\frac{1}{2} \gamma(1-\gamma) \mu-\frac{1}{2}(1+\lambda) \lambda \sigma_{m^{*}}^{2}$, we obtain the average growth of the foreign military threat (namely, $\alpha$ ), whose effect on the home country's economic growth rate and the ratio of total consumption-total wealth are

$$
\frac{\partial \phi}{\partial \alpha}=-\lambda
$$


and

$$
\frac{\partial \frac{C}{W}}{\partial \alpha}=\lambda
$$

when $\lambda>0$, we have $\frac{\partial \phi}{\partial \alpha}<0$ and $\frac{\partial \frac{C}{W}}{\partial \alpha}>0$; when $\lambda<0$, we have $\frac{\partial \phi}{\partial \alpha}>0$ and $\frac{\partial \frac{C}{W}}{\partial \alpha}>0$. These results show that when the elasticity of intertemporal substitution in consumption of the home country is large, higher foreign military spending leads to higher share of consumption and lower economic growth rate. Since $\lambda>0$ is equivalent to $0<\gamma<1$, which means the home country's intertemporal substitution in consumption is relatively elastic. Furthermore, when the intertemporal substitution is relative elastic, a larger foreign military spending increases the home country's marginal utility of military spending and its current military spending. The higher current consumption results in lower investment, and will cause lower economic growth in the long run. On the other hand, when its intertemporal substitution is inelastic, i.e. $\gamma>1$, the larger foreign military spending induces current lower consumption and growth rate, higher investment and higher economic level in the long run.

For the stochastic shock of the foreign military threat $\left(\sigma_{m^{*}}^{2}\right)$, its effect on the home country's economic growth rate and the ratio of total consumption-total wealth are

$$
\frac{\partial \phi}{\partial \sigma_{m^{*}}^{2}}=\frac{1}{2} \lambda(\lambda+1)
$$

and

$$
\frac{\partial \frac{C}{W}}{\partial \sigma_{m^{*}}^{2}}=-\frac{1}{2} \lambda(\lambda+1),
$$

when $-1<\lambda<0$, we have $\frac{\partial \phi}{\partial \alpha}<0$ and $\frac{\partial \frac{C}{W}}{\partial \sigma_{m^{*}}^{2}}>0$; when $\lambda>0$ or $\lambda<-1$, we have $\frac{\partial \phi}{\partial \alpha}>0$ and $\frac{\partial \frac{C}{W}}{\partial \sigma_{m^{*}}^{2}}<0$. The expressions above are more complex than the case of mean growth in foreign military spending. When intertemporal substitution in consumption of the home country is elastic (i.e. $0<\gamma<1$ ), higher variance of foreign military spending leads to less consumption-wealth ratio and faster economic growth. On the other hand, when intertemporal substitution in consumption of the home country is inelastic (i.e. $\gamma>1$ ), it depends on the value of $\lambda$. If the foreign military spending induces negative utility enough, namely $\lambda<-1$, larger volatility in the foreign military threat even can result in lower share of consumption and higher economic growth. If $-1<\lambda<0$, more volatility in the foreign military threat decreases ratio of consumption-wealth and increases economic growth rate.

In order to investigate the effects of stochastic shocks of the capital and foreign bond holdings on the economic growth, taking partial derivatives with respect to $\sigma_{k}^{2}$ and $\sigma_{b}^{2}$ of the expressions (23) and (24), we have

$$
\frac{\partial n_{1}}{\partial \sigma_{k}}=\frac{\frac{1}{\gamma}\left(r_{b}-r_{k}\right)+\sigma_{k b}-\sigma_{b}^{2}}{\left(\sigma_{b}^{2}-2 \sigma_{k b}+\sigma_{k}^{2}\right)^{2}},
$$




$$
\begin{aligned}
& \frac{\partial n_{1}}{\partial \sigma_{b}}=\frac{\frac{1}{\gamma}\left(r_{b}-r_{k}\right)-\sigma_{k b}+\sigma_{k}^{2}}{\left(\sigma_{b}^{2}-2 \sigma_{k b}+\sigma_{k}^{2}\right)^{2}}, \\
& \frac{\partial n_{2}}{\partial \sigma_{k}}=\frac{\frac{1}{\gamma}\left(r_{k}-r_{b}\right)-\sigma_{k b}+\sigma_{b}^{2}}{\left(\sigma_{b}^{2}-2 \sigma_{k b}+\sigma_{k}^{2}\right)^{2}}, \\
& \frac{\partial n_{2}}{\partial \sigma_{b}}=\frac{\frac{1}{\gamma}\left(r_{k}-r_{b}\right)+\sigma_{k b}-\sigma_{k}^{2}}{\left(\sigma_{b}^{2}-2 \sigma_{k b}+\sigma_{k}^{2}\right)^{2}} .
\end{aligned}
$$

Since parameter $\mu=n_{1}^{2} \sigma_{k}^{2}+n_{2}^{2} \sigma_{b}^{2}+2 n_{1} n_{2} \sigma_{k b}$, taking partial derivatives on $\mu$ with respect to $\sigma_{k}^{2}$ and $\sigma_{b}^{2}$, we obtain

$$
\frac{\partial \mu}{\partial \sigma_{k}^{2}}=C_{1} \frac{\frac{1}{\gamma}\left(r_{k}-r_{b}\right)-\sigma_{k b}+\sigma_{b}^{2}}{\left(\sigma_{b}^{2}-2 \sigma_{k b}+\sigma_{k}^{2}\right)^{2}},
$$

and

$$
\frac{\partial \mu}{\partial \sigma_{b}^{2}}=C_{2} \frac{\frac{1}{\gamma}\left(r_{b}-r_{k}\right)-\sigma_{k b}+\sigma_{k}^{2}}{\left(\sigma_{b}^{2}-2 \sigma_{k b}+\sigma_{k}^{2}\right)^{2}},
$$

where $C_{1}=\sigma_{b}^{2}-\sigma_{k b}+\frac{1}{\gamma}\left(r_{k}-r_{b}\right)+2\left(\sigma_{k b}-\sigma_{k}^{2}\right) \frac{\frac{1}{\gamma}\left(r_{k}-r_{b}\right)-\sigma_{k b}+\sigma_{b}^{2}}{\left(\sigma_{b}^{2}-2 \sigma_{k b}+\sigma_{k}^{2}\right)^{2}}+2\left(\sigma_{b}^{2}-\sigma_{k b}\right) \frac{\frac{1}{\gamma}\left(r_{b}-r_{k}\right)-\sigma_{k b}+\sigma_{k}^{2}}{\left(\sigma_{b}^{2}-2 \sigma_{k b}+\sigma_{k}^{2}\right)^{2}}$ and $C_{2}=\sigma_{k}^{2}-\sigma_{k b}+\frac{1}{\gamma}\left(r_{b}-r_{k}\right)+2\left(\sigma_{k}^{2}-\sigma_{k b}\right) \frac{\frac{1}{\gamma}\left(r_{k}-r_{b}\right)-\sigma_{k b}+\sigma_{b}^{2}}{\left(\sigma_{b}^{2}-2 \sigma_{k b}+\sigma_{k}^{2}\right)^{2}}+2\left(\sigma_{k b}-\sigma_{b}^{2}\right) \frac{\frac{1}{\gamma}\left(r_{b}-r_{k}\right)-\sigma_{k b}+\sigma_{k}^{2}}{\left(\sigma_{b}^{2}-2 \sigma_{k b}+\sigma_{k}^{2}\right)^{2}}$. From the results above, we find that the stochastic shocks to the capital stock and foreign bond holdings have the effects on the economic growth rate and the ratio between total consumption and total wealth as

$$
\begin{aligned}
\frac{\partial \phi}{\partial \sigma_{k}^{2}}= & \frac{\partial n_{1}}{\partial \sigma_{k}^{2}} r_{k}+\frac{\partial n_{2}}{\partial \sigma_{k}^{2}} r_{b}-\frac{1}{2}(1-\gamma) \gamma \frac{\partial \mu}{\partial \sigma_{k}^{2}} \\
= & \frac{\frac{1}{\gamma}\left(r_{k}-r_{b}\right)-\sigma_{k b}+\sigma_{b}^{2}}{\left(\sigma_{b}^{2}-2 \sigma_{k b}+\sigma_{k}^{2}\right)^{2}}\left(r_{b}-r_{k}-\frac{1}{2}(1-\gamma) \gamma C_{1}\right) \\
\frac{\partial \phi}{\partial \sigma_{b}^{2}}= & \frac{\partial n_{1}}{\partial \sigma_{b}^{2}} r_{k}+\frac{\partial n_{2}}{\partial \sigma_{b}^{2}} r_{b}-\frac{1}{2}(1-\gamma) \gamma \frac{\partial \mu}{\partial \sigma_{b}^{2}} \\
& =\frac{\frac{1}{\gamma}\left(r_{b}-r_{k}\right)-\sigma_{k b}+\sigma_{k}^{2}}{\left(\sigma_{b}^{2}-2 \sigma_{k b}+\sigma_{k}^{2}\right)^{2}}\left(r_{k}-r_{b}-\frac{1}{2}(1-\gamma) \gamma C_{2}\right), \\
\frac{\partial \frac{C}{W}}{\partial \sigma_{k}^{2}}= & \frac{1}{2}(1-\gamma) \gamma C_{1} \frac{\frac{1}{\gamma}\left(r_{k}-r_{b}\right)-\sigma_{k b}+\sigma_{b}^{2}}{\left(\sigma_{b}^{2}-2 \sigma_{k b}+\sigma_{k}^{2}\right)^{2}} \\
\frac{\partial \frac{C}{W}}{\partial \sigma_{b}^{2}}= & \frac{1}{2}(1-\gamma) \gamma C_{2} \frac{\frac{1}{\gamma}\left(r_{b}-r_{k}\right)-\sigma_{k b}+\sigma_{k}^{2}}{\left(\sigma_{b}^{2}-2 \sigma_{k b}+\sigma_{k}^{2}\right)^{2}}
\end{aligned}
$$

where $C_{1}$ and $C_{2}$ satisfy the expressions above. Thus, the expression of the derivatives in equations (37)-(40) are very complicated. Under general case it is difficult to determine 
whether the effect is positive or negative, if we don't know the specific values of the parameters. We specify the value of the parameters to get more information. In the case of the same average return level of capital and bonds, i.e. $r_{k}=r_{b}$, we can cancel out some complex terms, and we get $C_{1}=\sigma_{b}^{2}-\sigma_{k b}$ and $C_{2}=\sigma_{k}^{2}-\sigma_{k b}$ and

$$
\begin{aligned}
\frac{\partial \phi}{\partial \sigma_{k}^{2}} & =-\frac{1}{2}(1-\gamma) \gamma\left(\frac{\sigma_{b}^{2}-\sigma_{k b}}{\sigma_{b}^{2}-2 \sigma_{k b}+\sigma_{k}^{2}}\right)^{2}, \\
\frac{\partial \phi}{\partial \sigma_{b}^{2}} & =-\frac{1}{2}(1-\gamma) \gamma\left(\frac{\sigma_{k}^{2}-\sigma_{k b}}{\sigma_{b}^{2}-2 \sigma_{k b}+\sigma_{k}^{2}}\right)^{2} \\
\frac{\partial \frac{C}{W}}{\partial \sigma_{k}^{2}} & =\frac{1}{2}(1-\gamma) \gamma\left(\frac{\sigma_{b}^{2}-\sigma_{k b}}{\sigma_{b}^{2}-2 \sigma_{k b}+\sigma_{k}^{2}}\right)^{2} \\
\frac{\partial \frac{C}{W}}{\partial \sigma_{b}^{2}} & =\frac{1}{2}(1-\gamma) \gamma\left(\frac{\sigma_{k}^{2}-\sigma_{k b}}{\sigma_{b}^{2}-2 \sigma_{k b}+\sigma_{k}^{2}}\right)^{2}
\end{aligned}
$$

when $1>\gamma>0$, we have $\frac{\partial \phi}{\partial \sigma_{k}^{2}}<0, \frac{\partial \phi}{\partial \sigma_{b}^{2}}<0, \frac{\partial \frac{C}{W}}{\partial \sigma_{k}^{2}}>0$, and $\frac{\partial \frac{C}{W}}{\partial \sigma_{b}^{2}}>0$; when $\gamma>1$, we have $\frac{\partial \phi}{\partial \sigma_{k}^{2}}>0, \frac{\partial \phi}{\partial \sigma_{b}^{2}}>0, \frac{\partial \frac{C}{W}}{\partial \sigma_{k}^{2}}<0$, and $\frac{\partial \frac{C}{W}}{\partial \sigma_{b}^{2}}<0$. We find that a higher elasticity of intertemporal substitution in consumption (i.e. $0<\gamma<1$ ), will result in higher consumption-wealth ratio and lower economic growth in the home country, if there is more volatility in the return of capital or bonds. The mechanism is that, when intertemporal substitution in consumption is relative elastic, more stochastic shocks on capital or bonds reduce the share of investment and raise the share of consumption. In the long run, low level of investment will result in less output production and slow economic growth. In the case of $\gamma>1$, the results are just the opposite.

\section{Conclusion}

This paper studies the optimal military spending, trade and stochastic economic growth, which is one of the most important topic in macroeconomics. In our framework, the dynamic optimization method is used to research the endogenous stochastic economic growth problem in two-country military competitive model. In this model, we assume that the two countries, the home country and the foreign country, are in the state of military confrontation, but they trade with each other. Besides consuming domestic goods, the home country also consumes foreign goods through trade. Moreover, the total wealth of the home country consists of two parts, domestic capital stock and foreign bond holdings. In addition, we assume the military spending for the home country is regarded as special consumption goods.

Using specific utility function and production technology, we solve the Hamilton-JacobiBellman equation, and find the optimal military spending, the consumption of domestic goods and foreign goods, and the share of domestic capital stock and foreign bond holdings. 
Then, through comparative dynamics, we find that higher foreign military spending leads to slower (faster) economic growth of the home country if intertemporal substitution in consumption is elastic (inelastic); when intertemporal substitution in consumption is elastic, higher variance of foreign military spending leads to faster economic growth, but when intertemporal substitution in consumption is inelastic, economic can be faster or lower; if there is more volatility in the return of capital or bonds, a higher (lower) elasticity of intertemporal substitution in consumption will restrain (stimulate) economic growth in the home country.

The conclusions of this paper have important effect on theoretical meaning and applied value of military spending, trade and stochastic economic growth. First, based on this paper's study, we can continue to research the stochastic differential game models of twocountry military confrontation as well as consumption trade. Then, we also can combine the theoretical results and the empirical analysis to study the stochastic growth problem. In addition, the fact of China, Japan and Korea preparing currency swap will enlighten us in discussing the problems of currency and foreign exchange in military spending, trade and stochastic economic growth model.

\section{References}

[1] Abu-Bader S. and Abu-Qarn A. Government expenditures, military spending and economic growth: causality evidence from Egypt, Israel, and Syria [J]. Journal of Policy Modeling, 2003, Vol. 25, 567-583.

[2] Alptekin A. and Levine P. Military expenditure and economic growth: A meta-analysis [J]. European Journal of Political Economy, 2012, Vol.28, 636-650.

[3] Benoit E. Defense and Economic Growth in Developing Countries [M]. Lexington Books, Lexington, MA, 1973.

[4] Bertola G. and Drazen A. Trigger points and budget cuts: explaining the effects of fiscal austerity [J]. American Economic Review, 1993, Vol. 83, 11-26.

[5] Benoit E. Growth and defense in developing countries [J]. Economic Development and Cultural Change, 1977, Vol. 26, 271-280.

[6] Brito D. A dynamic model of an armaments race [J]. International Economic Review, 1972, Vol. 13, 359-375.

[7] Brito D. and Intriligator M. Formal Models of Arms Races [J]. Journal of Peace Secience, 1976, Vol. 2, 77-88. 
[8] Chang, W., Tsai H. and Lai C. Elects of anticipated foreign military threat on arms accumulation [J]. Southern Economic Journal, 1996, Vol. 65, 507-514.

[9] Deger S. Economic development and defence expenditure [J]. Economic Development and Defense Expenditure, 1986, Vol. 35, 179-196.

[10] Deger S. and Sen S. Military expenditure, spin-off and economic development [J]. Journal of Development Economics, 1983, Vol. 13, 67-83.

[11] Deger S. and Sen S. Optimal control and diIerential game models of military expenditures in less developed countries [J]. Journal of Economic Dynamics and Control. 1984, Vol. 7, 153-169.

[12] Deger S. and Smith R. Military expenditure and growth in less developed countries [J]. 1983, Vol. 27, 335-353.

[13] Faini R., Annez P. and Taylor L. Defence spending, economic structure and growth: evidence among countries and over time [J]. Economic Development and Cultural Change, 1984, Vol. 32, 487-498.

[14] Grinols E. and Turnovsky S. Risk, the finnancial market, and macroeconomic equilibrium [J]. Journal of Economic Dynamics and Control, 1993, Vol. 17, 1-36.

[15] Gong L. and Zou H. Military spending and stochastic growth [J]. Journal of Economic Dynamics and Control, 2003, Vol. 28, 153-170.

[16] Intriligator M. Strategic considerations in the Richardson model of arms races [J]. Journal of Political Economy, 1975, Vol. 83, 339-353.

[17] Kennedy G. The military in the third world [M]. Duchworth, London, 1974.

[18] Landau D. The Economic Impact of Military Expenditure [J]. The World Bank Working Paper Series 1138, 1993, The World Bank, Washington, DC.

[19] Lee C. A new explanation of arms races in the third world: a differential game model [J]. 2007, Vol. 3, 161-176.

[20] Lin P. and Lee C. Military spending, threats and stochastic growth [J]. Bulletin of Economic Research, 2012, Vol. 64, 8 C 19.

[21] Obstfeld M. Risk-taking, global diversification, and growth [J]. American Economic Review, 1994, Vol. 84,1310-1329.

[22] Pindyck R. and Solimano A. Economic instability and aggregate investment [J]. NBER Macroeconomic Annual, 1993, 259-303. 
[23] Polachek S. and Sevastianova D. Does conflict disrupt growth? Evidence of the relationship between political instability and national economic performance [J]. The Journal of International Trade and Economic Development,2012, Vol. 21, 361-388.

[24] Ramey G. and Ramey V. Cross-country evidence on the link between volatility and growth $[\mathrm{J}]$. American Economic Review, 1995, Vol. 85, 1138-1151.

[25] Richardson L. Arms and Security [M]. Boxwood Press, Chicago, 1960.

[26] Saaty T. Mathematical Models of Arms Control and Disarmament [M]. Wiley, New York, 1968.

[27] Shieh J., Chang W. and Lai C. An endogenous growth model of capital and arms accumulation $[\mathrm{J}]$. Defence and Peace Economics, 2007, Vol. 18, 557-575.

[28] Simaan M. and Cruz J. Formulation of Richardson's model of arms race from a diIerential game viewpoint [J]. Review of Economic Studies, 1975, Vol. 42, 534-544.

[29] van der Ploeg F. and de Zeeuw A. Perfect equilibrium in a model of competitive arms accumulation [J]. International Economic Review, 1990, Vol. 31, 131-146.

[30] Wijeweera A. and Webb M. Military spending and economic growth in sri lanka: a time series analysis [J]. Defence and Peace Economics, 2009, Vol.20, 499-508.

[31] Zou H. A dynamic model of capital and arms accumulation [J]. Journal of Economic Dynamics and Control, 1995. Vol 19, 371-393. 